\title{
A Innovative Section Collection Method Analysis for Digital Image Watermarking
}

\author{
K.P.Kaliyamurthie, G.Michael ,C.Nalini
}

\begin{abstract}
Another section district affirmation system for overpowering modernized picture watermarking is proposed in my paper. This procedure intends to pick a non covering highlight area set, which has the best power against different strikes and can shield picture quality in any case much as could reasonably be typical after watermarked. It from the outset plays out a re-sanctioned ambushing method utilizing some predefined strikes to study the liberality of each contender join locale.
\end{abstract}

As appeared by the assessment works out as intended, it by then handles a track-with-pruning system to look through an irrelevant essential once-over of capacities which can negate the most predefined ambushes. [1],[3],[5]

With a specific genuine target to refresh its protection from vague strikes under the obstacle of securing picture quality, the basic once-over of limits is then stretched out by including into some partner fragment territories. This work is portrayed as a multidimensional backpack issue and settled by a hereditary check based approach. The exploratory outcomes for Blend Stamp assaults on some benchmark pictures strengthen our yearning that the crucial once-over of limits can confine all the predefined strikes and its augmentation can improve the power against obscure ambushes. Separating and some unmistakable segment based systems, the proposed approach shows better execution in noteworthy modernized watermarking [2 ],[ 4],[6] Keywords :water marking,processing

\section{INTRODUCTION}

Advanced watermarking is the course toward implanting data into an electronic sign which might be utilized to attest its validness or the character of its proprietors, in a dubious way from a watermark for clear particular check. In front line watermarking, the pennant might be sound, pictures, or video. On the off chance that the pennant is duplicated, by then the data besides is passed on in the duplicate. A standard may pass on two or three undeniable watermarks in the mean time. The data to be presented in a flag is known as a robotized watermark, paying little respect to the path that in

Revised Manuscript Received on July 22, 2019.

KP.kaliyamurthie, Department of Computer Science and Engineering, Bharath Institute of Higher education and research, Chennai , IndiaEmail: kpkaliyamurthie@gmail.com

G.Michael,Department of Computer Science and Engineering, Bharath Institute of Higher education and research, Chennai , IndiaEmail: micgeo270479@gmail.com

C.Nalini, Department of Computer Science and Engineering, Bharath Institute of Higher education and research, Chennai , IndiaEmail: nalinicha2002@gmail.com two or three settings the verbalization moved watermark surmises the contrast between the watermarked pennant and the spread standard. The standard where the watermark is to be installed is called have flag. A watermarking structure is regularly detached into three explicit advances, embeddings, trap, and recognizing evidence. In embeddings, a figuring perceives the host and the information to be presented, and makes a watermarked standard.

By then the watermarked pushed standard is transmitted or set away, regularly transmitted to someone else. In the event that this individual reveals an improvement, this is known as a strike. While the change may not be noxious, the term trap ascends out of copyright insistence application, while privateers endeavor to discharge the moved watermark through adjustment. There are different potential changes, for instance, lossy load of the information, adjusting a picture or video, or deliberately including upheaval. [7],[ 9] ,[11]

Region is a calculation which is related with the assaulted standard to endeavor to expel the watermark from it. On the off chance that the pennant was unmodified amidst transmission, by then the watermark still is available and it might be disengaged. In vivacious modernized watermarking applications, the extraction calculation ought to be able to pass on the watermark decisively, paying little regard to whether the changes were solid. In delicate mechanized watermarking, the extraction figuring should come up short if any change is made to the flag. [8],[ 10], [12]

\section{EXISTING METHOD}

Vigorous picture watermarking plan for opposing geometric assaults and customary sign preparing assaults at the same time by two fundamental stages, the component point based watermark synchronization and the Discrete Wavelet Transform (DWT) based watermark installing. [13], [15] ,[ 17]

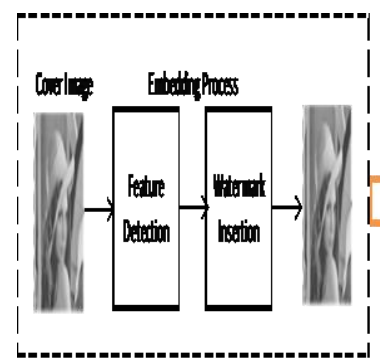

Figure 1 digital image watermarking methods

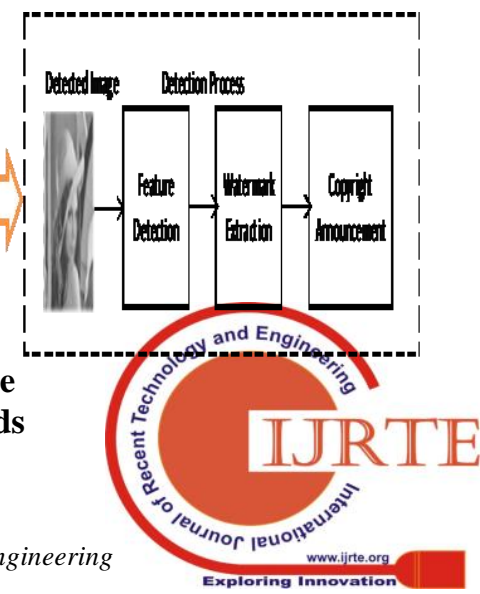


The trouble of choosing the most hearty and littlest element district set to be watermarked. Rehashed determination of powerful areas for watermarking to oppose comparable assaults. [14],[ 16], [18]

\section{PROPOSED METHOD}

We propose an element area choice strategy dependent on reproduced tackling and multidimensional rucksack issue (MDKP) enhancement systems. This technique can be incorporated into the component based watermarking plans to upgrade their heartiness against different sorts of assault. [20],[ 22], [24]

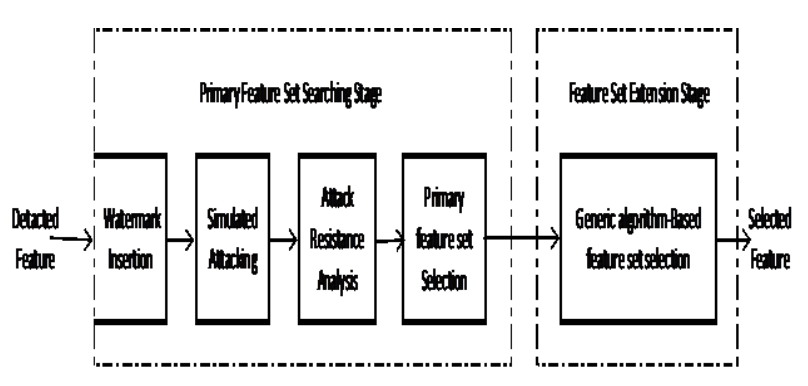

Figure 2 Block diagram of the proposed feature region selector

\section{FEATURE DETECTION}

We ask around two issues of existing section based plans in this paper: one is keeping away from rehashed choice of red hot areas for watermarking to limit comparable ambushes, and the other is the bother of picking the most solid and littlest part locale set to be watermarked. For the major issue, since the level of pixels in a district will be adjusted when a watermark is embedded into this domain, it is expected to pick non-covering zones for watermarking to maintain a strategic distance from a crucial corruption of picture quality. [38],[40]

Highlight identifiers perform explicit changes on motorized pictures to detach their near to highlights, going from a point to a test, and have been gotten a handle on in different applications, for example, Question insistence, database recovery, and improvement following. [26],[28],[30]

The Harris pioneer depends upon the consequent minute sort out. The second minute framework, moreover called the auto-relationship cross section, is as regularly as conceivable utilized for highlight revelation or for delineating neighborhood picture structures. This cross segment must be adjusted to scale changes to make it free of the picture affirmation. [31],[33],[35]

I ask around two issues of existing section based plans in this paper: one is staying away from emphasized choice of excited areas for watermarking to repudiate for all intents and purposes indistinguishableambushes, and the other is the burden of picking the most predominant and littlest part region set to be watermarked. For the basic issue, since the size of pixels in a district will be changed when a watermark is embedded into this locale, it is expected to pick nonoverlapping regions for watermarking to stay away from a huge debasement of picture quality. Coming about to getting picked zones from highlights perceived by the harris-Laplacian locator, watermark (implanting) on picked areas[19],[21],[23]

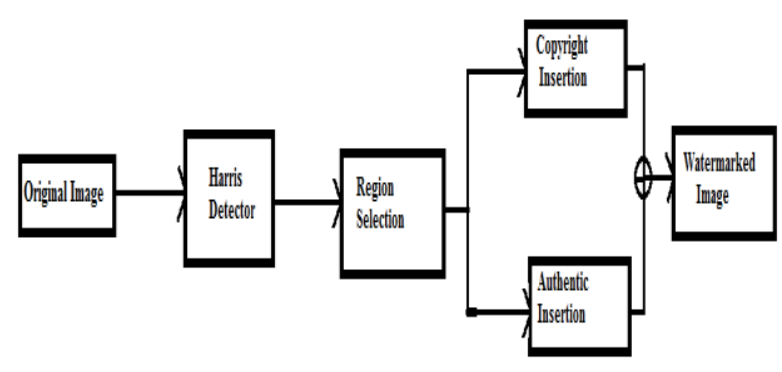

Figure 3 General process for

\section{Watermarked image}

Name the selected regions like a1, a2, a3 etc. Using message and key watermark on the selected regions and determine mse and psnr of the watermarked image. [25],[27],[29]

\section{RESULTS}

\section{A. INPUT IMAGE}

The JPEG image is given as an input image file for an experiment.

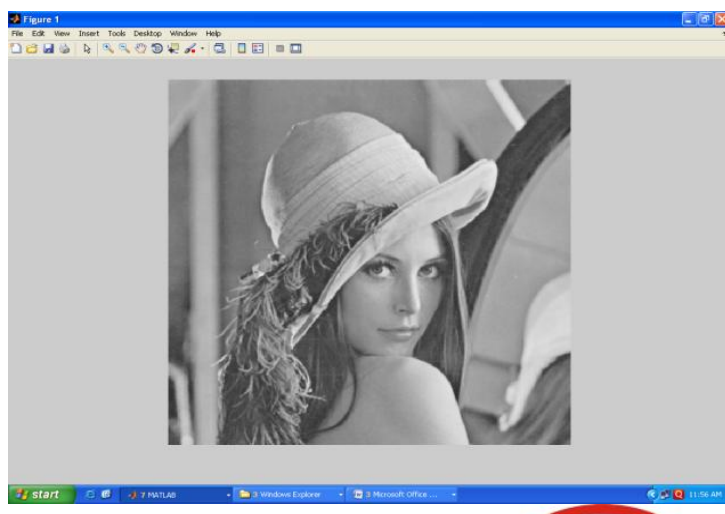

Figure 4 Input image 


\section{B. FEATURE DETECTION IMAGE}

A selection of non overlapping regions set, which has the higher corner response and better robustness against various attacks

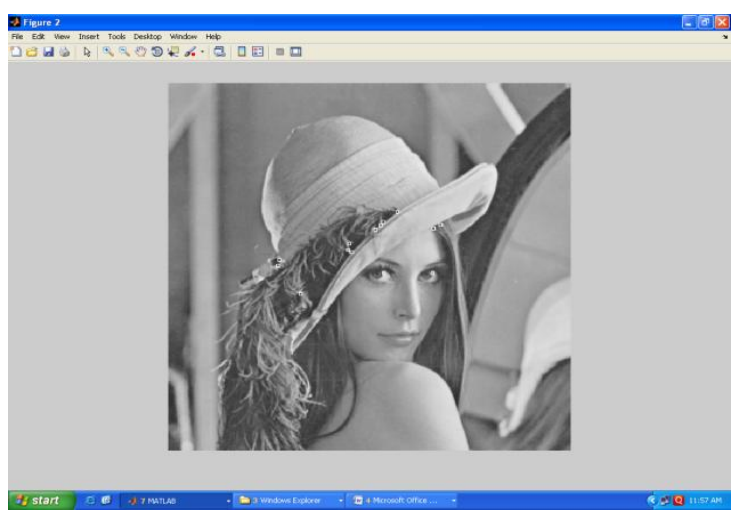

Figure 5 Feature detection image

\section{COPYRIGHT IMAGE}

The secrete message has been enter in this image.

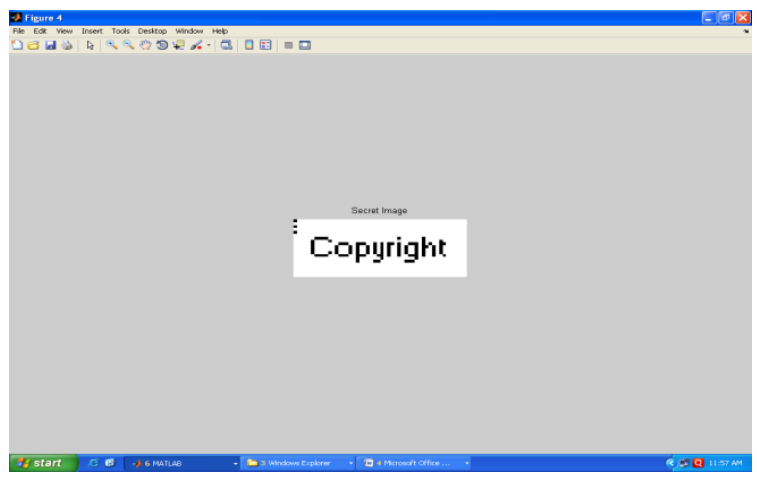

Figure 6 Copy right images

\section{AUTHENTIC INSERTION IMAGE}

The secret key has been entered in this image to secure the message[37],[39],[41]

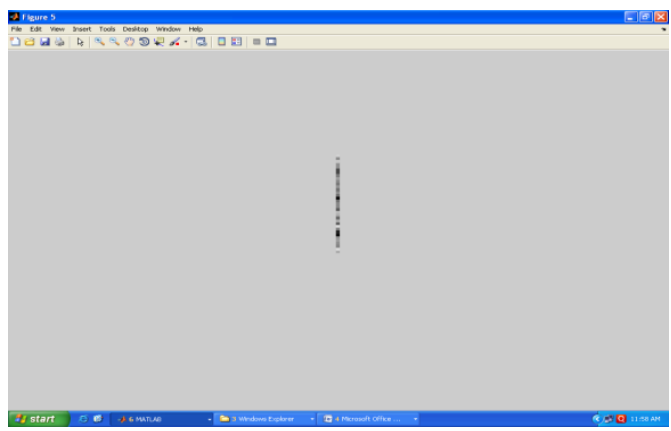

\section{Figure 7 Authentication insertion image}

\section{E. WATERMARKED IMAGE}

The watermark insertion has been done in this image and the output is shown below.

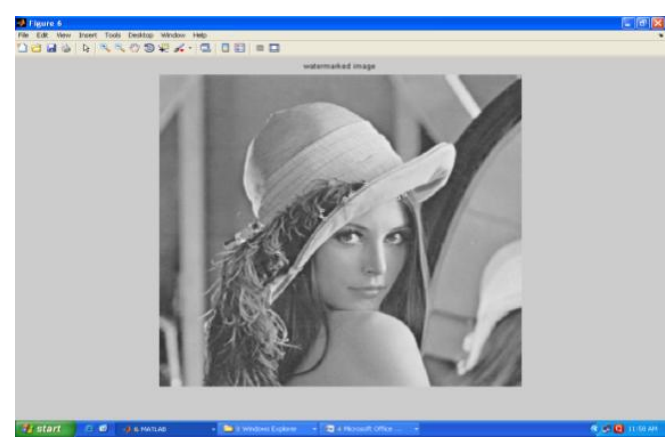

Figure:8

\section{RESULTS}

A novel strategy in view of the reenacted assaulting approach and the GA-based MDKP understanding technique is produced to choose the most satisfactory component areas for strong computerized picture watermarking under the limitation of saving picture quality. Contrasted and other element based watermarking techniques, the vigor against different assaults is altogether enhanced by the proposed strategy, and the picture quality subsequent to watermarking is as yet protected. It might be viewed as that our strategy devours excessively calculation time in estimating the power of highlight locales because of the mimicked assaulting. Be that as it may, by and by, as indicated by the exploratory outcomes, this isn't a worry if the embraced predefined assaults are illustrative, since few competitor include areas will be adequate to achieve full strength. Be that as it may, we are as yet endeavoring to build up a speedier strength estimation conspire and stretch out the proposed strategy to plan a safe advanced watermarking plan. [32],[34],[36]

\section{REFERENCES}

[1] A., Rangarajan K.,Algorithm for automaton specification for exploring dynamic labyrinths,Indian Journal of Science and Technology,V-6,I-SUPPL5,PP-4554-4559,Y-2013

[2] P. Kavitha, S. Prabakaran "A Novel Hybrid Segmentation Method with Particle Swarm Optimization and Fuzzy C-Mean Based On Partitioning the Image for Detecting Lung Cancer" International Journal of Engineering and Advanced Technology (IJEAT) ISSN: 2249-8958, Volume-8 Issue-5, June 2019

[3] Kumaravel A., Meetei O.N.,An application of non-uniform cellular automata for efficient cryptography,2013 IEEE Conference on Information and Communication Technologies, ICT 2013,V-,I-,PP-1200-1205,Y-2013

[4] Kumarave A., Rangarajan K.,Routing alogrithm over semi-regula tessellations, 2013 IEEE Conference on Information and Communication Technologies, ICT 2013,V-,I-,PP-1180-1184,Y-2013

[5] P. Kavitha, S. Prabakaran "Designing a Feature Vector for Statistical Texture Analysis of Brain Tumor" International Journal of Engineering and Advanced Technology (IJEAT) ISSN: 2249-8958, Volume-8 Issue-5, June 2019

[6] Dutta P., Kumaravel A.,A novel approach to trust based identification of leaders in social

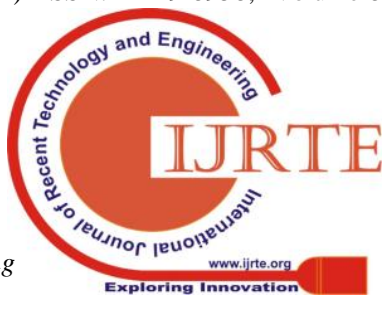




\section{A Innovative Section Collection method analysis for digital image watermarking}

networks,Indian Journal of Science and Technology,V-9,I-10,PP--,Y-2016

[7] Kumaravel A., Dutta P.,Application of Pca for context selection for collaborative filtering,Middle - East Journal of Scientific Research,V-20,I-1,PP-88-93,Y-2014

[8] Kumaravel A., Rangarajan K.,Constructing an automaton for exploring dynamic labyrinths,2012 International Conference on Radar, Communication and Computing, ICRCC 2012,V-,I-,PP-161-165,Y-2012

[9] P. Kavitha, S. Prabakaran "Adaptive Bilateral Filter for Multi-Resolution in Brain Tumor Recognition" International Journal of Innovative Technology and Exploring Engineering (IJITEE) ISSN: 2278-3075, Volume-8 Issue-8 June, 2019

[10] Kumaravel A.,Comparison of two multi-classification approaches for detecting network attacks,World Applied Sciences Journal,V-27,I-11,PP-1461-1465,Y-2013

[11] Tariq J., Kumaravel A.,Construction of cellular automata over hexagonal and triangular tessellations for path planning of multi-robots,2016 IEEE International Conference on Computational Intelligence and Computing Research, ICCIC 2016,V-,I-,PP--,Y-2017

[12] Sudha M., Kumaravel A.,Analysis and measurement of wave guides using poisson method,Indonesian Journal of Electrical Engineering and Computer Science,V-8,I-2,PP-546-548,Y-2017

[13] Ayyappan G., Nalini C., Kumaravel A.,Various approaches of knowledge transfer in academic social network,International Journal of Engineering and Technology,V-,I-,PP-2791-2794,Y-2017

[14] Kaliyamurthie, K.P., Sivaraman, K., Ramesh, S. Imposing patient data privacy in wireless medical sensor networks through homomorphic cryptosystems 2016, Journal of Chemical and Pharmaceutical Sciences 92.

[15] Kaliyamurthie, K.P., Balasubramanian, P.C. An approach to multi secure to historical malformed documents using integer ripple transfiguration 2016 Journal of Chemical and Pharmaceutical Sciences 92.

[16] A.Sangeetha,C.Nalini,"Semantic Ranking based on keywords extractions in the web", International Journal of Engineering \& Technology, 7 (2.6) (2018) 290-292

[17] S.V.GayathiriDevi,C.Nalini,N.Kumar,"An efficient software verification using multi-layered software verification tool "International Journal of Engineering \& Technology, 7(2.21)2018 454-457

[18] C.Nalini,ShwtambariKharabe,"A Comparative Study On Different Techniques Used For Finger - Vein Authentication", International Journal Of Pure And Applied Mathematics, Volume 116 No. 8 2017, 327-333, Issn: 1314-3395

[19]M.S. Vivekanandan and Dr. C. Rajabhushanam, "Enabling Privacy Protection and Content Assurance in Geo-Social Networks", International Journal of Innovative Research in Management, Engineering and Technology, Vol 3, Issue 4, pp. 49-55, April 2018.

[20] Dr. C. Rajabhushanam, V. Karthik, and G. Vivek, "Elasticity in Cloud Computing", International Journal of Innovative Research in Management, Engineering and Technology, Vol 3, Issue 4, pp. 104-111, April 2018.

[21] K. Rangaswamy and Dr. C. Rajabhushanamc, "CCN-Based Congestion Control Mechanism In Dynamic Networks", International Journal of Innovative Research in Management, Engineering and Technology, Vol 3, Issue 4, pp. 117-119, April 2018

[22] Kavitha, R., Nedunchelian, R., "Domain-specific Search engine optimization using healthcare ontology and a neural network backpropagation approach", 2017, Research Journal of Biotechnology, Special Issue 2:157-166

[23]Kavitha, G., Kavitha, R., "An analysis to improve throughput of high-power hubs in mobile ad hoc network", 2016, Journal of Chemical and Pharmaceutical Sciences, Vol-9, Issue-2: 361-363

[24] Kavitha, G., Kavitha, R., "Dipping interference to supplement throughput in MANET", 2016, Journal of Chemical and Pharmaceutical Sciences, Vol-9, Issue-2: 357-360

[25] Michael, G., Chandrasekar, A.,"Leader election based malicious detection and response system in MANET using mechanism design approach", Journal of Chemical and Pharmaceutical Sciences(JCPS) Volume 9 Issue 2, April - June 2016.

[26] Michael, G., Chandrasekar, A.,'Modeling of detection of camouflaging worm using epidemic dynamic model and power spectral density", Journal of Chemical and Pharmaceutical Sciences(JCPS) Volume 9 Issue 2, April - June 2016

[27] Pothumani, S., Sriram, M., Sridhar, J., Arul Selvan, G., Secure mobile agents communication on intranet,Journal of Chemical and Pharmaceutical Sciences, volume 9, Issue 3, Pg No S32-S35, 2016
[28] Pothumani, S., Sriram, M., Sridhar , Various schemes for database encryption-a survey, Journal of Chemical and Pharmaceutical Sciences, volume 9, Issue 3, Pg NoS103-S106, 2016

[29] Pothumani, S., Sriram, M., Sridhar, A novel economic framework for cloud and grid computing, Journal of Chemical and Pharmaceutical Sciences, volume 9, Issue 3, Pg No S29-S31, 2016

[30] Priya, N., Sridhar, J., Sriram, M. "Ecommerce Transaction Security Challenges and Prevention Methods- New Approach” 2016 ,Journal of Chemical and Pharmaceutical Sciences, JCPS Volume 9 Issue 3.page no:S66-S68

[31] Priya, N.,Sridhar,J.,Sriram, M."Vehicular cloud computing security issues and solutions" Journal of Chemical and Pharmaceutica Sciences(JCPS) Volume 9 Issue 2, April - June 2016

[32] Priya, N., Sridhar, J., Sriram, M. "Mobile large data storage security in cloud computing environment-a new approach" JCPS Volume 9 Issue 2. April - June 2016

[33] Anuradha.C, Khanna.V, "Improving network performance and security in WSN using decentralized hypothesis testing "Journal of Chemical and Pharmaceutical Sciences(JCPS) Volume 9 Issue 2, April - June 2016.

[34] Anuradha.C, Khanna.V, "A novel gsm based control for e-devices" Journal of Chemical and Pharmaceutical Sciences(JCPS) Volume 9 Issue 2, April - June 2016

[35] Anuradha.C, Khanna.V, "Secured privacy preserving sharing and data integration in mobile web environments " Journal of Chemical and Pharmaceutical Sciences(JCPS) Volume 9 Issue 2, April - June 2016

[36] Sundarraj, B., Kaliyamurthie, K.P. Social network analysis for decisive the ultimate classification from the ensemble to boost accuracy rates 2016 International Journal of Pharmacy and Technology 8

[37] Sundarraj, B., Kaliyamurthie, K.P. A content-based spam filtering approach victimisation artificial neural networks 2016 International Journal of Pharmacy and Technology 83.

[38] Sundarraj, B., Kaliyamurthie, K.P. Remote sensing imaging for satellite image segmentation 2016 International Journal of Pharmacy and Technology 83.

[39] Sivaraman, K., Senthil, M. Intuitive driver proxy control using artificial intelligence 2016 International Journal of Pharmacy and Technology $8 \quad 4$

[40] Sivaraman, K., Kaliyamurthie, K.P. Cloud computing in mobile technology 2016 Journal of Chemical and Pharmaceutical Sciences 92.

[41] Sivaraman, K., Khanna, V. Implementation of an extension for browser to detect vulnerable elements on web pages and avoid click jacking 2016 Journal of Chemical and Pharmaceutical Sciences 92.

\section{AUTHORS PROFILE}

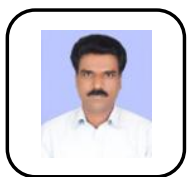

K.P.Kaliyamurthie, Professor, Department of Computer Science \& Engineering, Bharath Institute of Higher Education and Research, Chennai, India

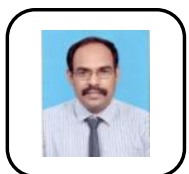

G.Michael ,Associate Professor, Department of Computer Science \& Engineering, Bharath Institute of Higher Education and Research, Chennai, India

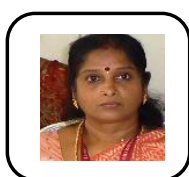

C.Nalini, Assistant Professor, Department of Compute Science \& Engineering, Bharath Institute of Higher Education and Research, Chennai, India 